\title{
Participação da Sociedade nos Processos de Gestão Governamental no Estado do Rio Grande do Sul Uma Análise do Contexto Atual
}

\author{
Jovani Augusto Puntel ${ }^{1}$ \\ Christine da Silva Schröeder ${ }^{2}$
}

http://dx.doi.org/10.21527/2237-6453.2018.44.351-382

Recebido em: 6/11/2015

Aceito em: 21/9/2017

\section{Resumo}

A gestão das atividades públicas vem sendo um desafio cada dia mais complexo, uma vez que a exigência por eficiência nas gestões empresariais chegou à esfera pública e, assim, cada vez mais os governos são desafiados ao enfrentamento dos processos burocráticos e à criação de mecanismos capazes de aproximar efetivamente Estado e sociedade. Diante de tal contexto, neste artigo, por meio de análise documental e entrevistas, analisa-se como se dá a relação entre planejamento governamental e participação, tomando como referência o processo de elaboração e acompanhamento do Plano Plurianual Participativo (2012-2015) e as demais ferramentas de participação adotadas pelo governo estadual do Rio Grande do Sul, no período de 2011 a 2014. Os principais resultados apontam para a necessidade de se aperfeiçoar tanto os instrumentos de planejamento governamental quanto os mecanismos de participação da sociedade civil nesses processos.

Palavras-chave: Planejamento. Desenvolvimento. Regionalização. Participação.

1 Doutor e mestre pelo Programa de Pós-Graduação em Desenvolvimento Regional da Universidade de Santa Cruz do Sul. jovaniaugusto@yahoo.com.br

2 Doutora e mestre em Administração pela Universidade Federal do Rio Grande do Sul. Professora da Escola de Administração da Universidade Federal do Rio Grande do Sul. christine@ea.ufrgs.br 


\title{
SOCIAL PARTICIPATION IN PUBLIC MANAGEMENT PROCESSES: AN ANALYSIS OF RECENT CONTEXT IN RIO GRANDE DO SUL, BRAZIL
}

\begin{abstract}
The management of the public activities is a complex challenge, and the demand for efficiency in the business managements reached the public sphere and more and more governments are challenged facing the bureaucratic processes and creating mechanisms of approximation between society and state. In this article, through documentary analysis and interviews, we analyze the relation between government planning and participation, taking as reference the process of construction of "Plano Plurianual Participativo" (2012-2015) and others instruments adopted by the state government of Rio Grande do Sul, Brazil, in the period from 2011 to 2014. The main results point to the need to improve both the instruments of government planning and mechanisms for civil society participation in these processes.
\end{abstract}

Keywords: Planning. Development. Regionalization. Participation. 
As concepções políticas e o modelo de desenvolvimento de cada período levam o Estado a reorganizar suas estruturas de planejamento e comando. Conforme Ianni (1986), o modo pelo qual Estado e economia se relacionam exprime as relações e influências recíprocas entre o poder econômico e o poder político. Da mesma forma que o Estado incorpora as demandas de regulação dos mercados, estabelece um novo ordenamento jurídico e de planejamento que repercute na sociedade e nas políticas de desenvolvimento, exprimindo também importantes aspectos da relação entre Estado e sociedade.

No que respeita ao planejamento governamental, Spink e Bresser-Pereira (1998) afirmam que, até o final dos anos 60 e início dos 70, os processos de aperfeiçoamento eram orientados pelas Nações Unidas e tratados como "reforma administrativa", englobando mudanças na administração pública, como a estrutura administrativa, fluxo de processos, estrutura de pessoal, entre outros. Com a inclusão de novas atribuições da administração pública, todavia, a partir da década de 90, passou-se a utilizar a expressão Reforma do Estado, trazendo uma ampla reflexão sobre as relações entre a sociedade e o aparelho estatal.

Essas discussões buscavam, de um lado, aperfeiçoar os processos de planejamento governamental até então desenvolvidos, além de buscar viabilizar canais de aproximação entre sociedade civil e Estado. Nesta direção, a Constituição Federal de 1988 institucionalizou os Planos Plurianuais (PPAs), que se configurariam como importantes instrumentos de planejamento com obrigatoriedade de formulação em todas as escalas de governo (federal, estadual e municipal), balizando a ação governamental e norteando a programação orçamentária do poder Executivo. Procurava-se assim criar instrumentos de planejamento e mecanismos de controle sobre as ações de governo.

Ao mesmo tempo, buscava-se criar mecanismos que viabilizassem a participação da sociedade nesse processo de planejamento. Logo, essa normatização buscou articular o planejamento oficial com a dimensão territorial, 
possibilitando que fossem articuladas diversas iniciativas de participação da sociedade nas três escalas de governo. Nesse sentido, envolver-se-iam múltiplos atores na formulação das políticas territoriais, repercutindo em importantes aproximações da sociedade com o Estado.

Favorecido pela reabertura democrática do Brasil no final da década de 80 e pelos direitos sociais assegurados pela Constituição Federal, no início da década seguinte emergiram diversos espaços participativos institucionalizados, a exemplo dos Conselhos Gestores de Políticas Públicas, Fóruns, Conferências, Orçamentos Participativos, etc. Muitas agências internacionais de financiamento também passaram a exigir maior participação da sociedade civil nas ações governamentais para liberar recursos financeiros.

De acordo com Nogueira (2003), nessa década a sociedade civil passou a ser vista como um recurso gerencial, um arranjo societal capaz de viabilizar tipos específicos de políticas públicas, assegurando mais controle social e possibilidade de maior democratização do próprio Estado. Criou-se, assim, uma expectativa de que a participação poderia contribuir para ampliar os canais de comunicação e negociação entre Estado e sociedade, tendo em vista definir políticas mais viáveis e justas com significativo impacto sobre a pobreza e a desigualdade, contribuindo para promover a democratização do Estado e a promoção do desenvolvimento (COELHO; FAVARETO, 2012).

No decorrer dos anos diversos governos têm procurado aperfeiçoar esse instrumento de planejamento. Vários autores apontam para a importância de os governos revisitarem e levarem mais a sério este instrumento de planejamento para que ele não se torne mais uma peça burocrática e obsoleta (CARDOSO JR., 2011a, 2011b; GARCIA, 2012; CARDOSO JR.; SANTOS; PIRES, 2015).

Entre os avanços desse instrumento, no Rio Grande do Sul, o Plano destaca as prioridades definidas por região, criando mecanismos para identificar regiões com maior carência de investimento. Constata-se progresso no sistema de monitoramento e avaliação, seja por intermédio de programas 
informatizados, ora estimulando a participação da sociedade civil, ora oferecendo dados para aferir as realizações do governo (CUNHA, 2011; FIALHO, 2012; ETGES et al., 2015).

No Rio Grande do Sul, o PPA para o período 2012-2015 (RIO..., 2011) destaca o elemento participação já no título do Plano, ressaltando a importância deste aspecto no conjunto do planejamento, e indica ainda a predisposição do governo em estabelecer uma relação mais estreita com a sociedade civil. Nesse sentido, o presente estudo busca analisar como se dá a relação entre planejamento governamental e participação, tomando como referência o processo de elaboração e acompanhamento do Plano Plurianual Participativo (2012-2015) e as demais ferramentas de participação adotadas pelo governo estadual do Rio Grande do Sul, no período de 2011 a 2014.

Como referência empírica para esse estudo utiliza-se os Planos Plurianuais, com ênfase no PPA 2012-2015, e nos demais instrumentos de participação criados pelo governo do Estado no mesmo período. Foi realizada pesquisa no website oficial do governo do Estado do Rio Grande do Sul, especificamente no Portal da Participação do Estado, no qual é apresentado o "Sistema Estadual de Participação Popular e Cidadã” (RIO..., 2012), que tem como objetivo integrar e modernizar as iniciativas de aprofundamento da democracia nas decisões da administração pública. Também foram entrevistados, entre o segundo semestre de 2012 e o primeiro semestre de 2013, alguns técnicos que atuaram nos setores de planejamento do governo estadual.

Foram entrevistadas, então, entre os meses de agosto de 2012 e julho de 2013, com uso de roteiros semiestruturados, pessoas envolvidas com os processos de participação popular, como técnicos e analistas da Secretaria do Planejamento e Gestão (Seplag/RS), membros da coordenação de objetivos estratégicos da Diretoria de Monitoramento Estratégico da Secretaria-Geral de Governo, parlamentares e assessores de comissões, além de participantes da sociedade civil presentes nos seminários de planejamento realizados na- 
quele mesmo período. Os dados obtidos por ocasião das entrevistas foram analisados, também, junto a documentos internos das Secretarias de Estado e à legislação pertinente.

Assim, este artigo inicia-se contextualizando o processo de planejamento governamental no Brasil, num período em que se visualizava o espaço de participação social como restrito, bem como um planejamento inicial voltado para o desenvolvimento via industrialização e expansão do sistema capitalista. Em seguida, são apresentados alguns elementos importantes sobre a institucionalização dos Planos Plurianuais como instrumentos de planejamento da ação pública, e, então, é abordado especificamente o contexto da participação no processo de elaboração e acompanhamento e as demais ferramentas de participação adotadas pelo governo estadual do Rio Grande do Sul, no período de 2011 a 2014. Encerrando, são apresentadas considerações finais.

\section{Contexto do Planejamento Governamental no Brasil}

O contexto do planejamento estatal vem conectado ao contexto político e socioeconômico de cada época, sendo possível identificar os aspectos hegemônicos ligados à complexidade técnica do próprio planejamento, diante dos diversos fatores que implicam o ato de planejar e executar determinada política, num território amplo e diversificado. A alternância dos partidos políticos que assumem o governo e as hegemonias componentes do jogo político expressam-se na definição das diretrizes de cada plano de desenvolvimento e no aparato de planejamento e gestão adotados.

A grande depressão econômica mundial, que culminou com a forte crise de 1929, apontou para grandes rupturas políticas e econômicas, que no Brasil se manifestaram por meio da Revolução de 1930. Conforme Ianni (1986), diante da impossibilidade de acomodar as tensões, o próprio Estado oligárquico se rompeu internamente e os novos governantes foram desafiados 
a acomodar interesses políticos e econômicos de diversos grupos, abrindo nesse período novas diretrizes governamentais, porém sem um diagnóstico objetivo dos problemas preexistentes.

As soluções adotadas após 1930 mostram "que o governo foi respondendo aos problemas e dilemas conforme eles apareciam no horizonte político, por injunções de interesses e pressões econômicas, políticas, sociais e militares" (IANNI, 1986, p. 15). Nesse sentido, a partir da Revolução de 1930 o Estado brasileiro buscou se reestruturar para criar condições para a conformação de um novo sistema político-econômico que representasse os conteúdos e interesses da burguesia emergente.

Estes movimentos de ajuste geralmente surgem de situações práticas e de clamor popular, que levam o Estado a tomar decisões intervencionistas, muitas vezes não antecedidas por estudos prévios. As crises econômicas e políticas impostas pela Segunda Guerra Mundial impuseram a diversos países, entre eles o Brasil, uma nova racionalidade e organização de uma tecnoestrutura estatal para orientar, também, o processo de expansão do setor terciário e industrial do país. Nesse sentido, houve

[...] uma combinação privilegiada de condições (economia de guerra, perspectivas de desenvolvimento industrial, problemas de defesa nacional, reestruturação do poder político e do Estado, nova constelação de classes sociais) que transformou a linguagem e a técnica do planejamento em um componente dinâmico do sistema político-administrativo. Ou melhor, a linguagem e a técnica do planejamento foram incorporadas de forma desigual e fragmentária, segundo as possibilidades apresentadas pelo sistema político-administrativo e os interesses dominantes do setor privado da Economia (IANNI, 1986, p. 68).

No mesmo período as políticas nacionais apresentavam como objetivo desenvolver o país, transformando as estruturas econômicas e sociais e estimulando o produtivismo via processos de industrialização, com o Estado buscando mecanismos para dar materialidade e sentido político à ideologia do 
industrialismo, e se fazendo necessária a montagem de estruturas e sistemas de planejamento governamental, por meio dos quais a missão desenvolvimentista pudesse se realizar naquele espaço-tempo.

A partir dessa opção foram criadas instituições de planejamento e as técnicas de planejamento passam a dar suporte às decisões governamentais. Era necessário criar bases materiais e políticas para viabilizar a transformação das estruturas locais, com vistas ao desenvolvimento nacional, desde as bases materiais até a difusão da ideologia do industrialismo e a adesão social ao projeto desenvolvimentista (IANNI, 1996; CARDOSO JR., 2011a).

O decorrer da História mostra que, ao longo desse período, o país passou por vários ciclos econômicos e produziu diversos planos de desenvolvimento, e, devido ao avanço do processo de industrialização brasileira na década de 40, questionava-se sobre que caminhos deveria seguir: se pela restauração do projeto liberal (orientado pela teoria das vantagens comparativas ricardianas e pela divisão internacional do trabalho) ou por um novo projeto de desenvolvimento por meio da industrialização induzida pelo Estado.

Aos poucos os conceitos de planejamento e desenvolvimento econômico passaram a ser apropriados tanto para governantes, políticos, empresários e técnicos, como para boa parte da sociedade brasileira. A partir da década de 50, com o avanço da "industrialização pesada", consolidou-se o projeto de orientação desenvolvimentista, que durou até os anos finais da década de 70 (CARDOSO JR., 2011a).

A década de 50 foi marcada pelo modelo desenvolvimentista, propagado teoricamente pela Comissão Econômica para a América Latina e o Caribe (Cepal) e assumido no Brasil por meio do Plano de Metas do governo Juscelino Kubitschek. O aumento da dependência tecnológica, acoplada ao padrão de industrialização, contribuiu para explicar a crise dos modelos econômico e político até então vigentes. 
O Plano de Metas marcou o início do planejamento indicativo, apontando onde o governo atuaria como agente econômico e onde deveria haver apenas a indicação para o setor privado. O Plano teve êxito no processo de industrialização da economia e na superação de pontos de estrangulamento que impediam o desenvolvimento nacional, porém trouxe desequilíbrios na balança de pagamentos e aumento das taxas de inflação (IANNI, 1986).

Os planos governamentais produzidos no âmbito do governo federal entre as décadas de 30 e 80 continham poucas diferenças entre si, apresentando em comum o empenho em condições de infraestrutura e de industrialização para fortalecer o setor industrial. Esses planos eram pontuais e elaborados para serem realizados a curto prazo. Conforme Brandão (2013), esse período ofereceu as bases materiais modernas de nosso país por meio dos "cinquenta anos gloriosos", em que foram desenvolvidos projetos de urbanização e de industrialização acelerada.

Com forte integração aos mercados dos países centrais, esse período proporcionou altas taxas de crescimento econômico e concentração de renda. Segundo o mesmo autor, nessa época as políticas se articulavam a partir de centros de poder que oscilavam entre o autoritarismo central e o "mandonismo local", intercalando períodos de centralização e de descentralização administrativa e política.

A partir da Constituição Federal de 1988 a atividade de planejamento é posicionada formalmente na agenda estatal por meio de um modelo que, a partir dos Planos Plurianuais (PPAs), integrava a Lei de Diretrizes Orçamentárias (LDO) e a Lei Orçamentária Anual (LOA). Esse conjunto de instrumentos busca estabelecer um processo de planejamento no qual o PPA indicaria os grandes rumos das políticas públicas, elencando os investimentos prioritários e estabelecendo metas qualitativas e quantitativas.

Por sua vez, a LDO desdobraria as metas do PPA, ano após ano, colocando-as nos padrões compatíveis com a realidade fiscal e estabelecendo as prioridades para serem contempladas no orçamento do ano seguinte. A 
LOA expressaria a execução prática das prioridades definidas anteriormente. Mediante a articulação desses três instrumentos buscava-se criar uma vinculação ao planejamento governamental, estabelecendo ações de longo, médio e curto prazos, e em todas as escalas de governo, tendo em vista buscar coerência na sua execução (CARDOSO JR.; 2011a; GARCIA, 2012).

Cabe destacar que a década de 90 marcou o início dos debates em torno da reforma administrativa do Estado brasileiro. Diante da diversidade regional, da amplitude do país e de tantas demandas, somadas à complexidade das questões ambientais, culturais e econômicas e das desigualdades sociais históricas, optou-se por uma abordagem que permitisse priorizar a sociedade e a valorização dos aspectos regionais na definição das prioridades das políticas estatais.

Diante desses desafios, no âmbito do Ministério da Integração Nacional (MI), é instituída a Política Nacional de Desenvolvimento Regional (PNDR) como política de governo, pelo Decreto ${ }^{\circ}$ 6.047, de 22 de fevereiro de 2007 (BRASIL, 2007), todavia os debates seguiram com avanços muito tímidos. ${ }^{3}$

As políticas que buscavam subsidiar o planejamento, reduzir as desigualdades regionais e promover a participação da sociedade civil no planejamento governamental também foram impulsionadas nesse período pela criação de diversas políticas de desenvolvimento territorial, como a criação dos Consórcios Municipais, os Territórios da Cidadania e a criação dos Territórios de Identidade. No Rio Grande do Sul as regionalizações mais utilizadas são as regiões dos Conselhos Regionais de Desenvolvimento (Coredes) e as Regiões Funcionais de Planejamento (RFP).

${ }^{3}$ No ano de 2013 foi publicada a "Nova Política Nacional de Desenvolvimento Regional PNDR II", em que é possível entender as principais pautas e o contexto da desta política no Brasil (BRASIL, 2013). 
Os Coredes foram criados em 1991 e institucionalizados no ano de 1994, durante o governo Alceu Collares (PDT), tendo entre os seus objetivos mobilizar a sociedade em torno dos problemas que afetam o desenvolvimento de suas regiões, contribuir para o planejamento governamental e promover iniciativas para o enfrentamento das desigualdades regionais (CARGNIN, 2014; COREDES, 2010). Buscava-se com essa regionalização viabilizar a participação da sociedade no planejamento governamental, bem como desenvolver um modelo de planejamento mais adequado à realidade de cada região. ${ }^{4}$

Por questões de objetivo, neste momento não aprofundamos a discussão acerca dos limites desse tipo de regionalização, mas destaca-se o esforço na tentativa de se valorizar os aspectos regionais no planejamento governamental, as potencialidades e fragilidades de cada região, buscando possibilitar um melhor arranjo para organizar a participação da sociedade civil no planejamento.

\section{Os Planos Plurianuais (PPAs)}

Farah Jr. (2012) explicita que o orçamento consiste em uma das ferramentas governamentais essenciais para o alcance dos objetivos esperados pela sociedade, requerendo que se repense a ação do Estado e o uso dos recursos orçamentários, observando exigência elevada de transparência, eficiência, eficácia e efetividade. A partir deste entendimento, os constituintes buscaram criar instrumentos que explicitassem as intenções de gasto do governo ao longo do tempo, além de organizar normativamente as intervenções parlamentares nos orçamentos, criando condições para o exercício regular de avaliação e controle das despesas públicas (GARCIA, 2012).

\footnotetext{
4 Atualmente o Estado do Rio Grande do Sul está organizado com 28 Coredes em atividade. Para fins de planejamento, os 28 Coredes estão organizados em 9 Regiões Funcionais de Planejamento (RFP). Para o planejamento oficial são reconhecidas as 9 RFPs, destacando-se que a regionalização dos Coredes, mesmo que não reconhecida oficialmente, também serve para subsidiar o planejamento governamental.
} 
A Constituição Federal de 1988, no seu artigo 165 (BRASIL, 2010), introduziu no ordenamento jurídico nacional a elaboração dos Planos Plurianuais de Desenvolvimento (PPAs), a Lei de Diretrizes Orçamentárias (LDO) e a Lei Orçamentária Anual (LOA), unificando os orçamentos anuais (Fiscal, Seguridade Social e de Investimento das Estatais) no Orçamento Geral da União (OGU).

Estas preocupações surgiram logo após o fim do regime militar, em 1985. Se até aquele período os planos eram de curta duração, dirigidos com total autonomia do poder Executivo e direcionados para conduzir o país à Segunda Revolução Industrial, num momento que a sociedade era menos complexa, após o regime militar, buscou-se formas de melhorar tais mecanismos, estabelecendo maior controle social sobre estes. Ademais, com a instauração do regime republicano, os Planos Nacionais de Desenvolvimento (PNDs) e a prestação de contas do poder Executivo ao Legislativo não eram apreciados pelos parlamentares e os orçamentos apenas cumpriam o ritual.

Para alterar essa prática os constituintes exigiram que o Executivo informasse suas prioridades na alocação de recursos financeiros, com objetivos e intenções de investimentos, evitando submeter ao Parlamento uma política de pacotes que faziam frente às intermináveis crises de financiamento do gasto público. A expectativa dos constituintes era a de que, com a institucionalização desse instrumento, se alcançaria maior capacidade organizativa e diretiva. Buscava-se assim atingir maior consistência e eficácia nas ações governamentais, estabelecendo mecanismos de controle democráticos sobre o ciclo orçamentário (SANCHES, 2006).

Sobre as fragilidades dos PPAs, faz-se necessário assinalar que a construção de uma visão estratégica precisa considerar as limitações que a realidade financeira estatal impõe a sua instituição. Nesse sentido, o planejamento está condicionado ao orçamento, tal como previsto nos dispositivos constitucionais. Ainda é importante considerar que o prazo de quatro anos abrangido pelo PPA pode ser curto para um horizonte adequado de plane- 
jamento, além de que tais planos geralmente são "desconstruídos" a partir do segundo ano de sua vigência, uma vez que os orçamentos posteriores não obedecem às prioridades nele contempladas, o que leva a sucessivas revisões.

\section{A Participação e seus Espaços na Esfera Governamental}

Bordenave (1994) define "participação" como a ação em que todos os cidadãos de fato têm parte nos processos produtivos, gerenciais e de usufruto dos bens sociais de forma equitativa, e que haveria seis maneiras de participar: de fato, pela simples existência da sociedade; espontaneamente, por livre escolha; imposta, geralmente por códigos morais ou por legislação específica; voluntária, quando os próprios participantes definem forma, objetivos e métodos da organização; provocada, impulsionada por um agente externo e, finalmente, concedida, quando organizações concedem aos cidadãos ou subordinados poder de decisão - seria este, particularmente, e ao menos em tese, o caso da participação em experiências de orçamento participativo, por exemplo.

Acerca dos graus de participação, Bordenave (1994) menciona que podem ser os seguintes: informação/reação, consulta facultativa (solicitação, de forma livre, de sugestões), consulta obrigatória aos subordinados (mas com decisão final da administração), elaboração/recomendação (em que os cidadãos são, por exemplo, convidados à proposição de políticas públicas), cogestão (envolvendo a gestão com decisões compartilhadas entre mecanismos de codecisão e colegiados - e neste caso se incluiria, em tese, o orçamento participativo), delegação (autonomia em campos antes reservados aos administradores) e, finalmente, autogestão (quando o coletivo determina meios, objetivos e controles, sem interferência de outras autoridades).

Entende-se que vem crescendo a participação popular em diferentes países, surgindo novas Organizações Não Governamentais e despertando a demanda social por maior transparência na gestão pública. Nesse sentido, o 
papel do cidadão iria além do papel de simples "contribuinte". De acordo com o que complementa Nogueira (2011), no entanto, não se faz suficiente abrir o aparato público à participação sem desburocratização dos processos (promovendo um movimento virtuoso de crítica e recriação organizacional), posto que, se os atores sociais se mobilizam mas não percebem avanço nas práticas, eles terminam por retroceder e, inclusive, abandonar a participação.

Souza (2006) confirma tal perspectiva. O autor associa a legitimidade do planejamento e da gestão das cidades ao efetivo controle e à deliberação por parte da coletividade, mas num contexto em que esta participação iria ainda além, como elemento em destaque, objetivando o rompimento da relação de mera tutela dos cidadãos pelo Estado: em outras palavras, objetivando a formação da cidadania e o aprofundamento de uma consciência de direitos.

A partir de meados dos anos 90, no Brasil, ocorre uma redefinição dos termos do debate acerca do papel do Estado e dos mecanismos de governança até então utilizados, sinalizando para o relativo esgotamento da agenda neoliberal de reformas pró-mercado e do gerencialismo da nova gestão pública. Esse debate renovado trouxe à cena as discussões sobre a Reforma do Estado e a importância de recuperar a sua capacidade de atuação.

Isto envolvia a necessidade de se construir burocracias sólidas e profissionalizadas, balizadas pelo tipo ideal weberiano. Implicaria buscar novos modelos de gestão pública com capacidade de recuperar suas dimensões política e social. Buscava-se enfrentar o desafio de se romper com uma visão da nova gestão pública focada na eficiência, e o desafio de se alcançar também maior eficácia social (CARDOSO JR., 2011a).

Nesse sentido, o Estado apresenta um amplo ordenamento jurídico que orienta sua burocracia e seus processos de planejamento e intervenção na sociedade, a fim de alcançar o desenvolvimento econômico e bem-estar social da população. Com o advento do sistema capitalista e a complexidade 
das relações entre mercado, Estado e sociedade, equalizar o planejamento estatal de forma a atender às demandas do desenvolvimento econômico e social do país tem se tornado um desafio cada vez mais complexo.

Desenvolver e executar um bom planejamento implica a compatibilidade dos esforços políticos, jurídicos e financeiros. Esse contexto está imbuído de forças hegemônicas que representam e defendem distintos interesses de setores, instituições e grupos que influenciam e complexificam sobremaneira as tomadas de decisão.

No Brasil, por volta de 1950, novos atores passaram a questionar a condução política do país, e por meio de movimentos populares compostos por associações profissionais, sindicatos, sem-terra, sem-teto, entre outros, constituíam uma expressiva demanda por diversos serviços públicos, como saúde, educação, assistência social, entre outros. Esse movimento, somado à crise econômica, pôs fim à ditadura militar e levou à promulgação da Carta Magna, mostrando que a sociedade pode ter consciência de seus direitos e manifestar-se para que sejam percebidos e garantidos pelo Estado.

Entende-se que, desde o seu surgimento, a sociedade civil contribui para a construção do processo democrático brasileiro, por meio de organizações sociais, lutas, associações, movimentos, etc., constantemente buscando o reconhecimento de seu projeto societário numa realidade contraditória pelo desenvolvimento do capital e, ao mesmo tempo, pelo desenvolvimento da cidadania. Os novos atores que emergiram na cena política necessitam de espaços na sociedade civil - instituições próprias para participarem de novos pactos políticos que redirecionam o modelo político vigente (AZEVEDO, 2010, p. 218).

Como salienta Reis (2003), a ciência política e a justiça social enfrentam questões complexas relacionadas a autoridade, mercado e solidariedade, que passam por mudanças profundas. No que diz respeito às transformações recentes nas relações entre Estado e nação, identidades coletivas são redefinidas por toda parte, cruzando fronteiras e desafiando autoridades 
nacionais para a garantia dos direitos das diversas populações. Dessa forma, o Estado precisa estar atento e constantemente reexaminar sua relação com o mercado e com a sociedade civil.

Nesta perspectiva, Nogueira (2011) recorda que a reforma do Estado brasileiro objetivou promover a introdução de estratégias inovadoras de gestão pública, com vistas à flexibilização de normas e descentralização de controles. A partir de tal descentralização, tais formas de gestão inovadora viriam na convergência da participação popular, a qual, juntamente com a accountability (prestação de contas, à sociedade, dos resultados das ações dos governantes), segundo Matias-Pereira (2007), contribuiria efetivamente para a evolução do debate atual acerca da administração pública brasileira.

\section{A Qualificação da Participação nos Processos de Elaboração dos PPAs no Rio Grande do Sul: alguns relatos e inferências}

Uma visão estratégica requereria, assim, um olhar de pelo menos uma década de continuidade e a incorporação das revisões decorrentes do monitoramento das ações planejadas. Essas fragilidades podem ser identificadas a partir das diretrizes dos PPAs do Rio Grande do Sul.

No Rio Grande do Sul, o primeiro PPA (1992 a 1995) foi encaminhado à Assembleia Legislativa pelo então governador Alceu Collares, por meio da Lei estadual $n^{\circ}$ 9.972/1991. As prioridades das diretrizes estavam voltadas para ações governamentais dirigidas ao desenvolvimento das áreas de educação, saúde e segurança (RIO..., 1991). Nesse governo foi instalado o Sistema de Acompanhamento das Ações Governamentais (AAG), ao qual cabia o controle e o acompanhamento físico-financeiro de todos os projetos, subprojetos e atividades, presentes ou não no Plano Plurianual, transparecendo que havia outro planejamento além do PPA. 
O segundo PPA (1996-1999) foi elaborado no governo de Antônio Britto. Nesse plano as orientações para as ações da administração estavam voltadas para a reforma do Estado, o saneamento financeiro, a recuperação da infraestrutura e a melhoria dos serviços das áreas de educação, saúde e segurança (RIO..., 1995).

A gestão do governo de Olívio Dutra (1999-2002) desenvolveu o PPA 2000-2003 (RIO..., 1999) e orientou o processo de mudanças na gestão pública do Estado pelo arcabouço legal e metodológico emitido pelo Decreto $n^{\circ} 2.829 / 98$ (BRASIL, 1998), que estabeleceu normas para a elaboração e execução do Plano Plurianual e dos Orçamentos da União. Desde então, toda ação finalística do governo deveria ser estruturada em programas e orientada para a consecução dos objetivos estratégicos definidos para o período do Plano, com detalhamento de objetivo, órgão responsável, valores, prazo de conclusão e fonte de financiamento.

Essas medidas apontavam para a necessidade de esforço para aperfeiçoar ainda mais esse instrumento de planejamento. Mesmo com essas alterações, todavia, Fialho $(2012$, p. 5), vai argumentar que [...] "quem se dispuser a analisar os Planos Plurianuais do Rio Grande do Sul para os períodos 1992-1995, 1996-1999 e 2000-2003 [...]" vai encontrar três documentos elaborados unicamente para atender às exigências formais da Constituição.

O Plano Plurianual 2004-2007 foi elaborado na gestão do governador Germano Rigotto (RIO..., 2003). Nesse PPA a orientação metodológica para elaboração dos programas deveria partir da identificação dos problemas, definindo objetivos e metas regionalizadas a serem alcançadas no período. $\mathrm{Na}$ tentativa de se melhorar o Plano, sempre que possível deveriam ser elaborados indicadores que permitissem aferir o alcance dos objetivos dos programas. Os programas foram orientados para promoção da inclusão social, atração de investimento e fomento ao desenvolvimento econômico, combate às desigualdades regionais e modernização da gestão e dos serviços públicos. 
A tentativa de colocar no Plano todas as ações com expressão orçamentária aproximou o PPA 2008-2011 (RIO..., 2007), elaborado durante o governo de Yeda Crusius, dos orçamentos anuais. A decisão, todavia, de encaminhar revisões apenas pontuais, que incorporassem as necessidades da Lei Orçamentária Anual, afastou o PPA do planejamento real dos órgãos, que por consequência não conseguiram abarcar todas as iniciativas necessárias dos quatro anos de governo.

$\mathrm{Na}$ opinião de um dos entrevistados na pesquisa, até hoje a gestão orçamentária e financeira não é feita com base nos objetivos estratégicos estabelecidos pelo PPA. Nos processos decisórios do planejamento, a Secretaria da Fazenda exerce um poder bastante grande e influi de modo significativo, predominando o objetivo fiscal sobre as outras esferas de planejamento. Nesse contexto o planejamento, que deveria ser um instrumento para subsidiar as tomadas de decisão dos gestores também em tempos de contenção fiscal, é condicionado por ela. Isso inverte o papel do planejamento e o torna uma ferramenta inócua.

Para outro entrevistado, o PPA 2008-2011 teve avanços importantes, mas não a ponto de os Programas serem desenvolvidos a partir da Visão Estratégica. Isto porque a Visão Estratégica era elaborada no mês de abril, e nessa época o processo de elaboração do PPA já se encontrava bem avançado, uma vez que tinha de ser encaminhado à Assembleia Legislativa no mês de maio. Dessa forma, o encadeamento lógico entre ambos ficava prejudicado. Além disso, havia o desafio de se desenvolver ferramentas de gestão que refletissem a complexidade do PPA, a necessidade de formação de uma rede de gestão e a perenização de uma agenda de qualificação do Plano.

As entrevistas evidenciaram a dificuldade de articulação existente entre alguns setores, dado que alguns deles concentram maior poder de decisão de forma a condicionar alguns aspectos postos no planejamento. Outra dificuldade estava relacionada aos prazos para elaboração do Plano 
e sua submissão à aprovação da Assembleia. Esta dificuldade mostra-se acentuada tendo em vista que, nos primeiros meses de cada gestão, os governos estão formando suas equipes e boa parte do quadro de pessoal está se apropriando da situação administrativa e dos processos burocráticos da gestão pública.

Além disso, o quadro técnico, o funcionalismo da área de governo, necessita de um espaço de tempo para se apropriar das diretrizes políticas do governo que está assumindo. Esses fatores não contribuem para a elaboração de um bom planejamento, permitindo que planos "paralelos" sejam postos em prática.

Cabe destacar que no governo Yeda Crusius foram criadas as Câmaras Setoriais para a coordenação de ações entre as Secretarias de Estado. Nessas Câmaras Setoriais eram avaliados 12 Programas Estruturantes (programas prioritários do seu governo), 4 deles na área de Desenvolvimento Econômico e Inovação, 6 na área de Desenvolvimento e 2 ligados às Finanças e Gestão Pública. Estes projetos recebiam tratamento orçamentário especial, tendo prioridade inclusive na liberação de recursos.

Nesta trajetória observa-se que, paralelamente à elaboração do PPA, outras formas de planejamento vinham sendo executadas, conforme a "necessidade e vontade" de cada governo. Apesar do arcabouço comum, cada governo buscou o "seu jeito" de planejar, fazendo que o PPA não evoluísse a ponto de se tornar referência para o planejamento e execução das ações governamentais. Neste contexto, é pertinente questionar os motivos de resistência para que o PPA não fosse usado como instrumento prático para o planejamento governamental.

Qual a necessidade de se criar planos paralelos? Existem várias explicações para essas questões, entre elas a de que os governos adotam planos paralelos, em tese menos sujeitos à rigidez das leis. Como explica Cardoso Jr. (2011a), o 
[...] planejamento é atividade altamente intensiva em gestão, daí que planejamento sem gestão adequada é processo especialmente sujeito a fracassos e descontinuidades de várias ordens, a ponto de parte da literatura sobre o assunto lançar mão da expressão "administração paralela" para designar soluções comumente adotadas por governantes ávidos por implementar e ser capazes de coordenar ações planejadas de investimento, etc., valendo-se, para tanto, não da estrutura já instalada de gestão, mas simplesmente criando estruturas paralelas de gerenciamento dos referidos planos de ação considerados mais estratégicos a cada momento ou situação (p. 13).

A trajetória histórica mostra a necessidade de se aperfeiçoar esses processos de planejamento e monitoramento dos PPAs. Muitos desses planos apresentam falhas metodológicas e estratégicas, ou são elaborados para cumprir determinações legais. Para uma maior compreensão do Ciclo Orçamentário, sugerimos a leitura das coletâneas organizadas por Giacomoni e Pagnussat (2006), Cardoso Jr. (2011b) e Cardoso Jr., Santos e Pires (2015), em que diversos autores fazem uma retrospectiva do planejamento governamental no Brasil e apontam para revisões importantes que podem aperfeiçoar esses processos, em especial os PPAs.

Ademais, por meio da análise dos planos realizados no Rio Grande do Sul, percebe-se também a descontinuidade desses planejamentos, que são abandonados na gestão do próprio governante. Essa ruptura com o plano, todavia, acentua-se a cada troca de governo. As mudanças de diretrizes em curto prazo evidenciam as dificuldades para o desenvolvimento regional, ao passo que o período de quatro anos, em nosso entendimento, apresenta-se reduzido para o enfrentamento de problemas crônicos de desenvolvimento socioeconômico das diferentes regiões.

O Estado brasileiro tem se organizado e ofertado diversos canais de participação para a sociedade contribuir na formulação e controle de suas políticas. No caso do Rio Grande do Sul, os diferentes governos buscaram caminhos distintos na elaboração dos PPAs. A partir, especialmente, da contribuição de Bordenave (1994), e dos dados relatados nesta pesquisa, pôde-se 
fazer algumas inferências acerca do grau de participação da sociedade gaúcha na elaboração do PPA - uma participação que, em tese, parte da proposta de cogestão, mas que, por vezes, não avança para além do grau da consulta obrigatória (BORDENAVE, 1994) aos subordinados.

O governo Alceu Collares (1991-1994) criou os Conselhos Regionais de Desenvolvimento (Coredes), tendo em vista proporcionar a participação da sociedade civil nas discussões sobre o planejamento de suas regiões e viabilizar um modelo de planejamento mais adequado para o enfrentamento das diferentes realidades que se apresentavam. Por sua vez, no governo Antônio Britto (1995-1998) foi instituída a Consulta Popular, também com o objetivo de estimular a participação da população na definição das prioridades regionais e elaboração do orçamento estadual (COREDES, 2010).

O governo Olívio Dutra (1999-2002) continuou a valorização da participação por meio da metodologia do Orçamento Participativo, originalmente praticada em Porto Alegre e, a partir de então, disseminada por todo o Estado. A proposta do governo Tarso Genro (2011-2014) foi a de aproveitar as experiências e metodologias existentes, criando um conjunto de ações e canais que permitisse à sociedade participar e acompanhar as realizações do governo (CARGNIN, 2014).

Conhecido como "Sistema de Participação" e coordenado pela Seplag/ RS, esse sistema teve a missão de fortalecer os instrumentos existentes e criar outros que facilitassem a participação cidadã no planejamento e no acompanhamento das ações governamentais. Entre os espaços de participação abertos à sociedade civil era possível participar nas Decisões Orçamentárias, por meio da elaboração do PPA Participativo e da Consulta Popular.

Os Coredes assumiram o papel de organizar a participação social e articular as demandas, articulando a comunicação entre sociedade civil e governo. Também foram criados diversos meios de comunicação entre sociedade e governo, diversos deles por intermédio de canais digitais via Internet (ETGES et al., 2015). 
No que respeita ao PPA, o governo Tarso Genro valorizou com bastante ênfase a participação popular, que chegou a constar como adjetivo no próprio Plano, tendo sido denominado de "PPA Participativo 2012-2015". No processo inicial de elaboração do Plano foi capacitada uma Rede de Planejamento para promover uma ampla discussão sobre as proposições da área dos diversos setores. Nestas discussões foram consideradas as demandas e resoluções dos Conselhos e Fóruns Setoriais, relacionados com as suas Pastas, e consideradas tais demandas na elaboração técnica dos Programas.

Os técnicos do Departamento de Planejamento fizeram uma síntese dos nove Objetivos Estratégicos, que são orientados pelos eixos Econômico, Regional, Social e Democrático - constituindo-se nas diretrizes estratégicas da Administração Pública Estadual, que orientaram a agenda de objetivos para alcançar o crescimento do investimento, do emprego e da renda; promover o desenvolvimento regional; elevar a qualidade de vida; aprimorar a cidadania; promover a paz e os valores republicanos (RIO..., 2012).

Pode-se constatar que, mesmo valorizando a participação, há um marco regulador e procedimentos normativos para a elaboração dos documentos oficiais. Considerando este aspecto, a construção das bases estratégicas do PPA seguiu várias etapas, contando inicialmente com a participação dos coordenadores dos setores, representantes das Secretarias e órgãos que compõem a administração governamental, e que legitimaram as propostas num Seminário de Governo, em março de 2011.

Nestes Seminários participaram os integrantes do gabinete do vice-governador, do Conselho de Desenvolvimento Econômico e Social, da Secretaria de Planejamento, Gestão e Participação Cidadã e do gabinete dos prefeitos. Desta forma os objetivos estratégicos ali estabelecidos serviram para motivar os Seminários Regionais e o processo de participação da população. 
Conforme identificado durante a pesquisa, os Seminários Regionais foram organizados em cada uma das nove Regiões Funcionais de Planejamento, quando o governo se dirigia à comunidade para apresentar o balanço da situação econômico-financeira do Estado e os objetivos estratégicos. Nestes eventos ouvia-se a população sobre as suas necessidades e se buscava sugestões para alavancar o desenvolvimento da região. Esses eventos reuniram 6 mil pessoas e mais de 350 instituições. A síntese dessas discussões integrou a base do PPA para o exercício de 2012 a 2015.

Como avalia um dos membros gestores da Secretaria do Planejamento e Gestão (atualmente Planejamento, Gestão e Participação Cidadã): “A discussão pública do Plano Plurianual, de forma participativa e deliberativa, é inédita no Brasil. Temos a responsabilidade de legitimar o que foi debatido nos seminários regionais e através das ferramentas virtuais, e apresentar programas que ofereçam alternativas à execução das principais demandas”.

Outra forma de viabilizar e qualificar a participação da sociedade no planejamento aconteceu por meio do Conselho do PPA, formado por um representante de cada Corede. Este Conselho teve como atribuições iniciais apreciar, emitir opinião e validar a proposta do PPA do governo do Estado para ser encaminhado à Assembleia Legislativa, além de acompanhar a execução do Plano. O Conselho do PPA Participativo era uma instância ainda em construção, mas capaz de contribuir com a qualidade no formato do Sistema de Participação Cidadã (RIO..., 2012).

Este processo buscava garantir que a construção do PPA fosse feita por "várias mãos" e que aos poucos as demandas de diversos setores e diferentes regiões do Estado pudessem ser contempladas no planejamento.

Procurando facilitar o acompanhamento cotidiano da população das ações públicas, o governo desenvolveu um canal para a Participação Digital, que ficou disponível à população por meio do acesso via Internet. Para a 
elaboração do PPA foi disponibilizado um formulário eletrônico, no qual a população podia enviar propostas para serem consideradas na elaboração do Plano.

Considerando o acesso à informação, o website agregou várias formas de informar e de se relacionar com a população, entre as quais pode-se destacar as Ações Participativas, a composição das Coordenadorias Regionais da Participação Popular e Cidadã, a relação dos Conselhos Regionais de Desenvolvimento (Coredes) e os orçamentos anuais.

Conforme Silva (2000), o Estado democrático está alicerçado no princípio da soberania popular, que impõe a participação efetiva e operante do povo na coisa pública, participação que não se exaure na simples formação das instituições representativas. As instituições se constituem um estágio da evolução do Estado democrático, mas não seu completo desenvolvimento. Assim, o princípio democrático a visa garantir os direitos fundamentais do cidadão.

Com este intuito, o governo buscou ampliar os canais de participação da sociedade civil no seu governo, porém um aspecto importante a ser observado é o da qualificação da participação cidadã. Percebeu-se, na pesquisa, que os fóruns e seminários são espaços mais qualificados que as participações individuais via Internet, quando via de regra os cidadãos demandam por infraestrutura e necessidades pontuais que se afastam de um planejamento de maior amplitude. Nesse sentido, ainda não conseguem evoluir propriamente para um grau de proposição de políticas públicas.

O principal objetivo do Sistema de Participação Cidadã no Rio Grande do Sul tem sido a constituição de um processo de diálogo, de escuta, por parte dos governantes e técnicos sobre as necessidades da população, no sentido de adequar a ação governamental às demandas indicadas pelos cidadãos.

Conforme dados obtidos por meio das entrevistas, entre abril e maio de 2011, foram colhidas aproximadamente 12.000 (12 mil) "propostas" de forma digital, sendo que 1.626 (mil, seiscentas e vinte e seis) foram publi- 
cadas e "discutidas/apoiadas" no Portal da Participação. As propostas não publicadas ou não atendiam à "Política de Publicação", ou eram repetidas (por exemplo, escolas mobilizaram sua comunidade escolar para solicitar algo, assim uma mesma demanda foi enviada 500 vezes). Essas contribuições foram analisadas e encaminhadas para os respectivos setores para que pudessem ser valorizadas na elaboração dos Programas.

Diante disso, participantes nos Seminários de Planejamento sugeriram que esse processo participativo fosse mais qualificado. Alguns participantes enfatizaram a importância de se realizar capacitações gratuitas (presenciais e virtuais) em controle social, planejamento, orçamento e políticas públicas para a sociedade civil organizada, para que a participação da sociedade seja mais qualificada, para além de uma relação de mera tutela dos cidadãos pelo Estado e o aprofundamento da consciência de direitos cidadãos (SOUZA, 2006). Outra sugestão foi a de realizar um debate entre sociedade, Coredes, Coordenação Regional, órgãos da administração direta e demais poderes sobre a Consulta Popular e o Orçamento Participativo, visando a melhorar o processo orçamentário, sem deixar de envolver o aspecto técnico que lhe é inerente.

Nesse sentido, o processo de qualificação da participação ainda tem um longo percurso a ser percorrido, para que evolua para além de um estado de consulta obrigatória (BORDENAVE, 1994), tendo em vista a complexidade da gestão pública, as manobras exercidas no meio político e, principalmente, pela ausência de uma "tradição" democrática, em que se vive um processo no qual muitas vezes a realização dos desejos individuais encontra-se acima do alcance do bem comum. Além do mais, as desigualdades de recursos organizacionais, informacionais e de infraestrutura podem afastar grande parte dos atores organizados e da própria sociedade civil desses processos decisórios.

Nesse entendimento, autores como Tatagiba (2002) e Dagnino, Olvera e Panfichi (2006) destacam que muitos espaços participativos têm apresentado procedimentos políticos pouco democráticos, na medida em que são compostos por atores que já possuem posições privilegiadas em 
outros espaços públicos, fazendo com que os interesses e as demandas de grupos ou de categorias tradicionalmente excluídas e com menos recursos permaneçam sem poder de influência. Além do mais, com acesso restrito aos recursos, muitas vezes a participação é conduzida, e não raramente acaba legitimando decisões que não a favorecem.

Diante dessas constatações, parece-nos relevante que se entenda e se destaque as virtudes da participação democrática, dada a importância de se reduzir o distanciamento existente entre os centros de poder e a sociedade civil. Acreditava-se que a participação da sociedade civil no governo estreitaria a comunicação entre os gestores públicos com os atores locais, contando com o fato de que o conhecimento desses atores locais sobre suas realidades ofereceria subsídios relevantes para a formulação e a execução das políticas públicas.

Conforme Coelho e Favareto (2012), o mecanismo causal implícito nesse processo é que com a ampliação da participação seria possível alcançar maior qualidade dos processos decisórios, permitindo que ocorresse uma justa distribuição dos recursos públicos, maior controle social e, por consequência, mais desenvolvimento, todavia torna-se importante cada vez mais verificar como de fato ocorre a tomada de decisão nesses espaços participativos.

Trata-se de identificar quem são os atores que participam, quem eles efetivamente representam e como as lideranças se relacionam com seus representados. Trata-se de buscar meios metodológicos que possibilitem que se verifique a democraticidade e a autenticidade desses espaços participativos. Conforme mencionado por estes mesmos autores, nem sempre esses espaços participativos são tão democráticos quanto aparentam ser, logo, faz-se importante compreender a heterogeneidade da sociedade civil e do Estado e levar em conta as desigualdades de recursos organizacionais, financeiros e humanos existentes entre eles. 


\section{Considerações Finais}

No modelo democrático participativo tem-se a concepção de sociedade civil como um elemento central, constituído por setores organizados da sociedade que, reconhecendo sua heterogeneidade e sendo contemplada pelo sistema político, assumem o papel de assegurar o caráter público do Estado. Nota-se que os anos mais recentes representam um constante avanço no que diz respeito à criação de processos democráticos, planejamento e participação da sociedade civil no Estado. No caso brasileiro, esses processos devem ser valorizados, ante um momento histórico no qual somente a primeira geração está vivendo um ciclo completo de democracia.

O Brasil passou por um longo período de colonização, herdando uma cultura de subordinação de vários séculos. Passada essa época, adentra-se à ditadura militar, com impactos significativos às expressões democráticas. A partir deste histórico, surgem fragilidades do Estado, do regime democrático e do próprio sistema de planejamento, cujas instâncias de participação, todavia, não podem ser menosprezadas em seu potencial, posto que tais possibilidades de participação, mesmo que limitadas, permitem exercer o controle social e fazer com que os dirigentes políticos legislem de forma mais responsável, aproximando Estado e sociedade em torno de objetivos comuns.

Pôde-se constatar, neste estudo, que a participação da sociedade civil no planejamento ainda permanece no grau da consulta obrigatória (BORDENAVE, 1994), a despeito dos avanços consideráveis em termos de possibilidades e canais para se fazer ouvir em diferentes instâncias governamentais. Nesse contexto, a participação individual é considerada pouco autêntica, posto que os atores não se apropriaram do modelo de funcionamento do sistema político e de planejamento.

Abre-se, assim, caminho à manipulação da população para fins de legitimação de ações governamentais que não representam necessariamente os interesses da coletividade, mas os de grupos particulares, legitimando interesses dos governantes ou de grupos com maiores capacidades de recursos. 
A questão da representatividade dos atores sociais nesses espaços participativos também é um elemento que deve ser analisado com cuidado, identificando pontos de tensão e de cooperação entre sociedade e governo, uma vez que não raramente pessoas utilizam a institucionalização para se promoverem individualmente. Ademais, é importante que se analise como são tomadas as decisões pela própria sociedade civil, estando atentos para que ela não seja também reprodutora de disputas e práticas excludentes. Nesse contexto é fundamental que se busque compreender o efetivo alcance da participação social na gestão pública e sua capacidade de criar e modificar estruturas, não somente de alocar recursos.

Nesse sentido, os fóruns regionais podem ser mais apropriados para discussões mais qualificadas. No Rio Grande do Sul, os processos de regionalização, principalmente por meio dos Coredes, mostram-se mecanismos importantes que podem ser utilizados tanto para aperfeiçoar as instituições e organizações regionais quanto para a qualificação de lideranças, possibilitando que se ofereça maior contribuição para o planejamento governamental.

No contexto de elaboração dos PPAs percebe-se de maneira ampla que este instrumento precisa ser aperfeiçoado. Como sinalizado por Garcia (2012) e Cardoso Jr. (2011b), um dos limites desse instrumento de planejamento é que muitas vezes ele apresenta um detalhamento praticamente igual ao do Orçamento, assumindo mais o caráter de Orçamento Plurianual do que propriamente de plano. Isto faz com que tais instrumentos se sobreponham e mostrem-se de pouca utilidade para auxiliar a tomada de decisão dos gestores públicos. Além disso, percebeu-se como ainda usual a elaboração de outros modelos de planejamento que fogem do rigor orçamentário e da fiscalização governamental e da própria sociedade civil.

No Rio Grande do Sul, entretanto, pode-se considerar que por haver uma equipe técnica responsável pelo planejamento, os PPAs têm agregado valor ao longo dos anos, principalmente em termos de regionalização, monitoramento e participação social. As experiências de regionalização do Rio Grande do Sul, os Conselhos Regionais de Desenvolvimento, a plataforma 
de comunicação e os diálogos do governador com a sociedade são elementos que ensejam maior valorização pelo fato de terem sido estruturados para fortalecer o processo democrático, permitindo maior transparência das ações governamentais perante a sociedade.

Trata-se de continuar os esforços para se aperfeiçoar esse sistema de planejamento, bem como oferecer alternativas para que a participação da sociedade se torne mais autêntica e efetiva. A despeito das fragilidades apontadas no processo, convém destacar a relevância dessas iniciativas como elementos ainda em construção, e nesse sentido, talvez a maior preocupação deva ser com a continuidade desses processos, posto que muitas vezes eles são interrompidos e fragilizados em momentos de crise política e fiscal, mas principalmente em cada troca de governo. Esta não continuidade constitui um fator de entrave à evolução dos graus de participação propostos por Bordenave (1994).

\section{Agradecimentos}

Os autores agradecem à Fundação Instituto de Pesquisa Econômica Aplicada (Ipea) pelo financiamento da pesquisa que originou este artigo.

\section{Referências}

AZEVEDO. D. A. de. Movimentos sociais, sociedade civil e transformação social no Brasil. Saber Acadêmico, n. 9, jun., p. 214-223, 2010.

BORDENAVE, J. E. D. O que éparticipação. São Paulo: Brasiliense, 1994.

BRANDÃO, C. A. Pacto federativo, reescalonamento do Estado e desafios para a integração e coesão regionais e para a legitimação de políticas regionais no Brasil. In: BRANDÃO, C.; SIQUEIRA, H. (Org.). Pacto federativo, integraşão nacional e desenvolvimento regional. São Paulo: Fundação Perseu Abramo, 2013.

BRASIL. Decreto $n^{\circ}$ 2.829, de 29 de outubro de 1998. Estabelece normas para a elaboração e execução do Plano Plurianual e dos Orçamentos da União, e dá outras providências. Brasil: Presidência da República, Brasília, 1998. 
Decreto $n^{\circ}$ 6.047, de 22 de fevereiro de 2007. Institui a Política Nacional de Desenvolvimento Regional - PNDR e dá outras providências. Brasil: Presidência da República, Brasília, 2007.

. Nova Política Nacional de Desenvolvimento Regional PNDR II. Brasília: Ministério de Integração Nacional Secretaria de Desenvolvimento Regional, nov. 2013.

. Constituição da República Federativa do Brasil. Título VI - Da Tributação e do Orçamento, Capítulo II - Das Finanças Públicas, Seção II - Dos Orçamentos. Texto consolidado até a Emenda Constitucional $n^{\circ}$ 64, de 4 de fevereiro de 2010. Brasil: Presidência da República, Brasília, 2010.

CARDOSO JR., J. C. Planejamento governamental e gestão pública no Brasil: elementos para ressignificar o debate e capacitar o Estado. Texto para discussão 1584. Brasília: Ipea, 2011a.

(Org.). A reinvenção do planejamento governamental no Brasil. Brasília: Ipea, 2011b. V. 4.

CARDOSO JR., J. C.; SANTOS, J. C.; PIRES, R. R. (Org.). PPA 2012 - 2015: a experiência subnacional de planejamento no Brasil. Coletânea: Pensamento estratégico, planejamento governamental \& desenvolvimento no Brasil contemporâneo; Livro 3. Brasília: Ipea, 2015.

CARGNIN, A. P. Políticas de desenvolvimento regional no Rio Grande do Sul: vestígios. Marcas e repercussões territoriais. Brasília: Ministério da Integração Nacional, 2014.

COELHO, V. S. P.; FAVARETO, A. Conexões entre participação, democracia e desenvolvimento: investigação dos impactos políticos e distributivos da participação social. In: LAVALLE, A. (Org.). O horizonte da política. Questões emergentes e agendas de pesquisa. São Paulo: Unesp, 2012.

COREDES. PRÓ-RS IV. Propostas estratégicas para o desenvolvimento regional do Estado do Rio Grande do Sul, 2011-2014. Porto Alegre: Passografic, 2010.

CUNHA, C. G. da. O Plano Plurianual como instrumento de planejamento e gestão. 2011. Trabalho (Conclusão de Curso) - UFRGS, Curso de Especialização em Administração Pública Eficaz, Escola de Administração da UFRGS, Porto Alegre, 2011.

DAGNINO, E.; OLVERA, A.; PANFICHI, A. Para uma leitura da disputa pela construção democrática na América Latina. In: DAGNINO, E.; OLVERA, A.; PANFICHI, A. (Org.). A disputa pela construção democrática na América Latina. São Paulo: Paz e Terra, 2006.

ETGES, V. et al. Planejamento e gestão governamental na esfera estadual: uma análise comparativa dos processos, conteúdos e sistema de acompanhamento dos PPAs. Relatório de Pesquisa. In: GARDOSO JR., J. C.; SANTOS, J. C.; PIRES, R. R. (Org.). PPA 2012 - 2015: a experiência subnacional de planejamento no Brasil. Coletânea: pensamento estratégico, planejamento governamental \& desenvolvimento no Brasil contemporâneo; Livro 3. Brasília: Ipea, 2015. 
FARAH JR., M. F. Orçamento público e gestão governamental. In: SILVA, C. L. da (Org.). Políticas públicas e desenvolvimento local: instrumentos e proposições de análise para o Brasil. Petrópolis: Vozes, 2012.

FIALHO, R.C. O PPA no Rio Grande do Sul: da exigência legal ao instrumento de gestão. 2012. Disponível em: <http://www.seplag.rs.gov.br/upload/O_PPA_NO_ RS.pdf>. Acesso em: 15 jan. 2013.

GARCIA, R.C. PPA, o que é e o que pode ser. Brasília: Ipea, 2012. Disponível em: <http:// www.en.ipea.gov.br/agencia/images/stories/PDFs/politicas_sociais/bps_20_artigoespecial.pdf> Acesso em: 17 fev. 2013.

GIACOMONI, J.; PAGNUSSAT, J. L. (Org.). Planejamento e orçamento governamental. Coletânea. Brasília: Enap, 2006. V. 2.

IANNI, O. Estado e planejamento econômico no Brasil (1930-1970). Rio de Janeiro: Civilização Brasileira, 1986.

MATIAS-PEREIRA, J. Manual de gestão pública contemporânea. São Paulo: Atlas, 2007.

NOGUEIRA, M. A. Sociedade civil, entre o político-estatal e o universo gerencial. Revista Brasileira de Ciências Sociais, v. 18, n. 52, jun. 2003.

. Um Estado para a sociedade civil: temas éticos e políticos da gestão democrática. São Paulo: Cortez, 2011.

REIS, E.P. Reflexões leigas para a formulação de uma agenda de pesquisa em políticas públicas. Revista Brasileira de Ciências Sociais, v. 18, n. 51, p. 11-14, fev. 2003.

RIO GRANDE DO SUL. Secretaria da Coordenação e Planejamento. Lei n 9.972, de 15 de agosto de 1991 - Plano Plurianual 1992-1995. Rio Grande do Sul: Secretaria da Coordenação e Planejamento, Porto Alegre, 1991.

. Secretaria da Coordenação e Planejamento. Lei no 10.531, de 2 de agosto de 1995 - Plano Plurianual 1996-1999. Rio Grande do Sul: Secretaria da Coordenação e Planejamento, Porto Alegre, 1995.

. Secretaria da Coordenação e Planejamento. Lei n 11.365, de 5 de agosto de 1999 - Plano Plurianual 2000-2003. Rio Grande do Sul: Secretaria da Coordenação e Planejamento, Porto Alegre, 1999.

. Secretaria da Coordenação e Planejamento. Lei $n^{\circ} 11.945$, de $1^{\circ}$ de agosto de 2003 - Plano Plurianual 2004-2007. Rio Grande do Sul: Secretaria da Coordenação e Planejamento, Porto Alegre, 2003.

. Secretaria do Planejamento e Gestão. Lei no 12.749, de 20 de julho de 2007 - Plano Plurianual 2008-2011. Rio Grande do Sul: Secretaria do Planejamento e Gestão, Porto Alegre, 2007.

. Secretaria do Planejamento e Gestão. Lei no 13.808, de 18 de outubro de 2011 - Plano Plurianual 2012-2015. Rio Grande do Sul: Secretaria do Planejamento e Gestão, Porto Alegre, 2011. 
Sistema Estadual de Participação Popular e Cidadã. 2012. Disponível em: <http://www.portaldaparticipacao.rs.gov.br>. Acesso em: 30 out. 2013.

SANCHES, O. M. O ciclo orçamentário: uma reavaliação à luz da Constituição de 1988. In: GIACOMONI, J.; PAGNUSSAT, J. L. (Org.). Planejamento e orçamento governamental. Coletânea. Brasília: Enap, 2006. V. 2.

SILVA, J. A. Curso de Direito Constitucional Positivo. São Paulo: Malheiros Editores, 2000.

SPINK, P. K.; BRESSER-PEREIRA, L. C. (Org.). Reforma do Estado e Administração Pública Gerencial. Rio de Janeiro: Ed. da Fundação Getúlio Vargas, 1998.

SOUZA, M. L. de. A prisão e a ágora: reflexões em torno da democratização do planejamento e da gestão das cidades. Rio de Janeiro: Bertrand Brasil, 2006.

TATAGIBA; L. Os Conselhos Gestores e a democratização das políticas públicas no Brasil. In: DAGNINO, E. (Org.). Sociedade civil e espaços públicos no Brasil. São Paulo: Paz e Terra, 2002. 